\title{
Migraine plus epilepsy
}

\author{
Walter C. Alvarez, M.D.
}

As I NOTED in another paper, whenever I see a patient with a severe, bizarre, or long-lasting migraine refractory to treatment, I suspect that I am dealing with migraine plus something else -such as a mild psychosis, an unrecognized epilepsy, a cerebral arteriosclerosis, or a constitutional inadequacy. Elsewhere, I have described a series of patients with migraine plus a mild psychosis. Now I present cases in which migraine was complicated by a mild epilepsy or an epileptic carrier state.

In 1912, I saw a man in his thirties with a migraine so severe that I suspected the presence of an extra component. I learned that he had a brother whose life has been ruined by epilepsy. I put my patient on the then-used bromides, and he was much relieved. Ever since then, whenever I have seen a patient with an unusually severe migraine, or migraine that persisted in a severe form into the patient's later years, I have asked if he had epileptic or violent-tempered or psychotic forebears, and often I have learned that he had some. I am particularly suspicious of an epileptic component when the patient keeps getting severe migraines without any obvious exciting cause. Then I wonder if the triggers could be little epileptic storms in the brain, and, when I get electroencephalograms made, I may find the expected signs of seizure activity. As most physicians know, in cases of pure migraine in which no epilepsy occurs in the patient's family, the electroencephalograms are normal. ${ }^{4}$

Are migraine and epilepsy related? Several authorities have claimed that migraine and epilepsy are related, but I cannot helieve this.

1] The 2 diseases usually appear in different types of persons with different temperaments.

2] Migrainous persons, who know of no epilepsy or psychosis in their family, usually have normal electroencephalograms.

3] Anticonvulsive drugs do not help the person with a pure migraine.

4] Persons with ordinary, mild migraine rarely have epilepsy or epileptic relatives.
However, when I went at the investigation the other way around and started with relatives of epileptics, I found $21 \%$ had had sick headaches. ${ }^{1}$ In 1933, Peter Bassoe, starting with 200 epileptic patients, found that $28 \%$ had some migrainous relatives. ${ }^{2}$ Like me and some others, he had found very few migrainous patients with epilepsy or with epileptic relatives.

At first glance, the high incidence of $\mathrm{mi}$ graine among the relatives of epileptics suggests a relationship between the 2 diseases, but when I studied the relatives of 574 psychotic and alcoholic patients, I found that 23\% had had migraine. So far as I know, no one has suggested that migraine is related to psychosis; in fact, as some observers have noted, most migrainous persons are unusually sensible and sane.

The probable explanation for the figures obtained is that, when migraine is uncomplicated, a high percentage of the patients have such a mild syndrome that they never mention it to a physician. But when patients have migraine plus a mild psychosis or epilepsy, the syndrome is usually so severe and incapacitating that when they visit a physician they will surely complain about it.

The incidence of migraine. Unfortunately, no one can guess what the incidence of migraine is in the United States or in any particular group within the United States. No 2 men agree on what is mild migraine, and most of them diagnose the disease only in its less common severe forms. Because migraine is a disease of bright, wide-awake, well-educated persons, the incidence in any particular group must depend on the average education and social position of the people in the group. The figures to be found in the literature range from 1.6 to $53 \%$.

Reported cases of migraine plus epilepsy. In his great book, Megrim and Sick Headache written in 1873, Edward Liveing, mentioned families in which migraine was mixed with 
psychosis and epilepsy. ${ }^{3}$ He told of a migrainous woman with an epileptic brother and sister. He said, "Her own Megrim, after recurring regularly once a month for 23 years, was replaced by epilepsy." Another patient "had a sister, epileptic, and her own Megrim was replaced after two years by epilepsy."

Other cases have been reported in which migraine and epilepsy alternated, but I think what the stories mean is that 2 diseases were inherited by 1 person. Often when asked about this, the patient will say, "Yes, that's right; I got my migraine from one ancestral group and my epilepsy from the other."

\section{CASE REPORTS}

Following are reports of a number of patients with 2 inheritances. Several of these reports would be more convincing if I could say what the electroencephalogram was like, but, unfortunately, in many cases, the patient was from out of town, could not wait for an appointment to get an electroencephalogram, or did not feel he could afford one.

Why the case histories are brief. To those many readers who may be distressed because in the following abstracts of case histories I do not give details about physical, laboratory, and $x$-ray findings, I will say that all these people were thoroughly examined in several great medical centers, usually several times, and nothing pertinent was found besides what I mention here. I do not see any sense in wasting many pages on purely negative findings. Actually, during the hundreds of careful and extensive studies made on migrainous persons, I rarely found any organic disease and very rarely found any organic disease that could explain the frequency of the spells. Migrainous attacks come out of a hereditarily predisposed brain and are seldom worsened by any disease below the neck. In a few patients marked hypertension was perhaps causing the attacks to come more frequently. Many of the women patients had had their gallbladder or a myomatous uterus removed, but none had been cured.

The evidence given here is suggestive. In the cases now to be reported, I cannot prove that the severity of the migrainous spells was due to the extra factor of an epileptic inheritance; but, in most of my patients in whom migraine was particularly severe, I suspect it was because I found an extra psychotic or epileptic element in the person's illness or heredity. In medicine, when one keeps observing something again and again, it is likely to be significant.

\section{EPILEPSY IN THE FAMILY}

A young woman with a terrible migraine had a mother with a history of seizures which were apparently epileptic in nature. Of her 2 sisters, 1 was depressed and 1 had a violent temper. My patient's brilliant brother was drinking himself to death. In this case, my impression was strong that my eccentric and violent-tempered patient was a carrier of epilepsy.

A woman with one of the worst migraines I ever saw had a lot of queer relatives. Her migrainous father had an epileptic nephew and a psychotic great-nephew. The migrainous mother had a psychotic sister (who had a hysterectomy when she was 20) and also an insane first cousin. My patient had a sister and a brother both with violent temperssuch as one finds in some epileptic patients. The sister had a crazy, alcoholic daughter and 2 alcoholic sons.

An attractive, able, unmarried business woman of 50 had had frequently recurring and severe migraines for 37 years. Her mother was "a devil" with a terrible temper. Several members of the mother's family were much like her-some of them alcoholic and some insane. On the patient's father's side, there was epilepsy. It was not surprising that a woman with such poor genes on both sides of her family should have had a stormy temperament and a life racked by violent emotions.

An unmarried woman of 26 said that, although her severe migraines no longer occurred, she still suffered so grievously from spells of paralyzing fatigue (suggesting migraine) that she could not hold a job. She was afraid to marry because her health was so frail. Among her near relatives were several epileptics and alcoholics.

\section{MEN WITH SEVERE MIGRAINE}

A man who was pleasant and good-tempered began with severe, migrainous headaches at the age of 48 . I suspected a connection be- 
tween this severe and late-coming migraine and his poor nervous inheritance. His father's brother drank himself to death, and his father, a confirmed grouch, had an ungovernable temper which suggested an epileptic carrier state. The child of this father's sister had epilepsy, and my patient's sister and brother were epileptic. Unfortunately, I could not get an electroencephalogram made.

A business man was still having severe migraine at the age of 45 . With the headache, he had short explosive attacks of diarrhea, such as many psychotic persons have. When I asked him where he had gotten a poor nervous inheritance, he said his mother and her 2 sisters were insane and his sister's child had epilepsy. I regret that the man would not stay to let me get an electroencephalogram made.

At the age of 50, an intelligent, odd-looking scientist was still having terrible migraines 2 or 3 times a week. Often the pain was so unbearable he had to take 3 or 4 injections of morphine. He had a somewhat dysrhythmic electroencephalogram. His work kept him tense, but this didn't seem to be enough to explain all the trouble. All his sibs had an epileptic type of violent temper, and 1 sister was psychotic. My impression was that the great irritability of his nervous system was due to a tendency to epilepsy.

A highly sensitive, 40-year-old man was still suffering from severe migraines with nausea and vomiting. His mother's father had epilepsy.

\section{PERSONS WITH MIGRAINE PLUS EPILEPSY OR} WHAT APPEARED TO BE EPILEPSY

In this section, I am describing cases in which a migrainous type of headache was particularly severe in the case of a woman or man who suffered from either definite epilepsy or what looked like an epileptic carrier state. Sometimes the person had a violent temper and sometimes a dysrhythmic electroencephalogram.

Very interesting to me was the problem of a 24-year-old man who had been complaining of terrible unilateral headaches and vomiting for eight years. The pain in his head was so severe that sometimes he screamed. He had no typical scotoma, but, in the spells, his eyes were very sensitive to light. For two days before a spell, he would have a migrainous type of aura in which he was unusually amorous. Sometimes he had a constant type of headache, such as one sees in some relatives of psychotic patients. During many spells, he would be apathetic and would keep rubbing his left eye with the back of his hand as if he were in an attack of psychomotor epilepsy. As a boy, 1 eye tended to turn in. Several able internists who had studied him carefully had recognized the migrainous element in his illness but had been unable to help him with ergotamine.

Only after 3 talks with the man's father did I draw out the reluctant admission that, from boyhood on, the patient had been epileptic. Occasionaly, he would be found lying unconscious on the floor. After several more talks with the father, I learned that the young man had lost jobs because of falling down at work. He had a violent temper, and, as I expected, Dr. Gibbs found a typically epileptic type of dysrhythmic electroencephalogram. His father and his father's father were fierytempered and could have been carriers of epilepsy. The mother was an able womana carrier of migraine. After administration of Dilantin, the young man made an immediate and remarkable recovery. After a few years, he reported that he could get by without the anticonvulsive drug.

One of the worst cases of intractable migraine I ever had to deal with was that of a young, quick-tempered, married woman whose attacks were so severe that sometimes she would vomit for days and become unconscious. The only thing that would relieve her was methadone. Her face often twitched, even when she wasn't in a spell. I could not get a history of bad heredity, but almost all the members of her family were neurotic. The fact that her electroencephalogram showed a marked dysrhythmia suggested that she was a carrier of epilepsy. Unfortunately, she was no better on anticonvulsive drugs.

Another woman with such a severe migraine that I could not help her much also had a markedly dysrhythmic electroencephalogram. Her father had been a good-for-nothing who had deserted his family. Because the woman came from a great distance, I do not know if 
she was helped with the Dilantin I prescribed.

A woman of 44 had severe migraine, severe epilepsy, and a dysrhythmic electroencephalogram. From time to time, she had a hysterical type of contraction of a segment of muscle in the left upper quadrant of her abdominal wall. For five or ten minutes, the muscle would feel like a door knob. She also had spells of hysterical bloating. From 10 to 20 times a day, she had transient jabs of abdominal pain-typical equivalents of epilepsy. Because of these pains, a surgeon had explored her abdomen on two occasions-to no purpose.

A woman's very severe migraine was a puzzle to me until I learned of queer spells she was having which almost certainly were equivalents of epilepsy. Also, I learned that once she had had an attack of grand mal in which she had fallen heavily. Her mother had fainting spells, apparently epileptic in nature.

A pleasant, nice-looking, married woman was still having occasional severe, prostrating attacks of migraine at 45 . For years she had had epileptic seizures and attacks of nervous bloating. Her father drank heavily. Her son was an epileptic, but possibly he got at least some of his trouble from his father who appeared to be a carrier of epilepsy.

A highly migrainous divorcée of 50 was sickly and complaining, always hypochondriac, often unable to work, and often getting herself operated on for some supposed disease. Her story of severe convulsions, temper tantrums, and terrible nightmares in infancy suggested that she had had epilepsy in her childhood. She admitted she had had such a violent temper that several husbands in succession had walked out on her.

A woman with a severe form of migraine had a mild epilepsy and a dysrhythmic electroencephalogram. Occasionally, she had a short spell of diarrhea. Perhaps, as an equivalent of migraine or epilepsy, she had spells of nausea lasting two weeks at a time. She had a number of alcoholic and psychotic relatives, plus some relatives who behaved like highly irritable carriers of epilepsy.

At 51, an unhappy divorcée was still having severe migraines. She had a dysrhythmic electroencephalogram and a number of epileptic forebears.
A man of 39 told me that, in his early years, he had had very severe migraines. Later, they changed into spells of dizziness, with "almost blackout" and with feelings of fear that he would shake all over and fall down. After much questioning, I learned that in his youth he had had episodes of grand mal. At times he was alcoholic. Epilepsy ran through his father's family.

A man of 52 with terrible migraines looked like a sullen, degenerating type of epileptic. He was so irascible that he was often discourteous to customers in his store. As I expected, he had a dysrhythmic electroencephalogram. He had a migrainous mother, an insane brother, and another brother who had an idiot child.

Diagnosis was difficult in the case of an intelligent, nervous, and typically migrainous married woman who, in her early years, had had frequent sick headaches. After the age of 30 , her syndrome changed and consisted of spells of great distress in her abdomen. This interfered so much with her breathing that she often felt as if she were choking. For years these spells were severe and long-lasting. They would come at any time of day or night. She could not identify any triggering cause. At times she would regurgitate her food.

Eventually, I drew out the story that one night, three years before I saw her, her mother had heard her thrashing about and had found her in a fit. She was hard to waken, and, next morning, like an epileptic, she had no memory of the episode. Later, she had another similar spell and, following that, a series of spells that resembled petit mal. Suggestive of an epileptic carrier state were such facts as that she and her mother both had violent tempers and that the mother's nephew was epileptic. My patient's father was a drunkard. Unfortunately, I could not get her to stay for the making of an electroencephalogram.

A middle-aged, highly irritable woman had had severe migraines in her childhood. When I saw her, she had what looked like an epileptic carrier state. In her childhood, she had had terrible nightmares, frequent tantrums, and spasms of rage and had always been rebellious -refusing to do anything she was asked to do. She walked and talked in her sleep. She 
had severe chorea at the age of 12 . At the age of 17, she contracted a foolish marriage and soon was deserted by her husband. For a while after that, she drank a pint of whiskey a day. Then she went into a depression. In later life, she had a severe constant pain around her rectum-a pain such as one sees in some mildly psychotic persons. Her grandfather, who came of insane stock, was a restless man with severe migraines. The patient's sister went insane after years of alcoholism. She had alcoholic uncles on both sides of the family. I could not learn of any epileptic relatives. With her stormy, emotional nature, this woman's migraines should have been severeand they were.

\section{MILD MIGRAINE AND AN}

\section{EPILEPTIC INHERITANCE}

The next few reports are inserted here just to show that in some cases an epileptic or a person with an epileptic inheritance can have a mild type of migraine.

A 48-year-old woman had a mild migraine in spite of the fact that twice a year she had an attack of grand mal. She had a typically epileptic electroencephalogram. Her mother who was epileptic and diabetic had a sister who was insane. The patient's sister was at times depressed.

A woman with mild migraine had a mild epilepsy with some dysrhythmia in her electroencephalogram. Her hot-tempered father was depressed at times, and his father was alcoholic. The patient's brother was diabetic and hot-tempered. Her mother was migrainous.

A 24-year-old woman with mild migraine and a dysrhythmic electroencephalogram was subject to attacks of grand mal. She had several psychotic relatives but knew of no epileptic ones.

A woman with a mild migraine complained only of short spells of depression. She probably was a carrier of epilepsy because her father's mother was epileptic, and she (the patient) had an epileptic child. Her father's sister was insane, and a great-grandfather drank himself to death.

\section{SUMMARY}

When one has to deal with a person with unusually severe migraine or migraine still severe in the person's later years, one should think of a second component-which sometimes is epilepsy or an epileptic carrier state.

The writer gives several reasons for his inability to accept the thesis that migraine is closely related to epilepsy. It seems more probable that, when epilepsy and migraine are found together in a patient, they are due to 2 inheritances.

Persons with simple or typical or mild migraine seldom have epileptic relatives, but in a study made by the author, $21 \%$ of 99 relatives of epileptics had had migraine. This does not prove a relationship between the 2 diseases, because, in a group of 574 relatives of psychotic or alcoholic persons, 23\% were found to have migraine, and migraine and psychosis do not appear to be at all related. Persons with pure migraine have normal electroencephalograms, and they are not helped by anticonvulsive drugs. Persons suffering from migraine are usually very differentphysically, intellectually, socially, and temperamentally-from persons suffering from epilepsy.

A series of cases are described in which persons with a severe form of migraine had either what looked like an epileptic inheritance or actual epilepsy in themselves.

It is well to recognize epilepsy when it is added to migraine because epilepsy can explain so easily the severity of the syndrome and occasionally can lead to a cure with the help of anticonvulsive medication. A few epileptic patients will be found to have mild migraine.

\section{REFERENCES}

1. Alvarez, W. C.: Practical Leads to Puzzling Diagnoses: Neuroses That Run Through Families. Philadelphia, J. B. Lippincott, 1958. Chap. 3

2. Bassoe, P.: Migraine. J.A.M.A. 101:599, 1933.

3. Lrverng, E.: On Megrim and Sick Headache and Some Allied Disorders: Contribution to Pathology of Nerve-Storms. London, Churchill, 1873.

4. Grbss, F., and Grbss, E.: Personal communication. 


\section{Neurology}

Migraine plus epilepsy

Walter C. Alvarez

Neurology 1959;9;487

DOI 10.1212/WNL.9.7.487

This information is current as of July 1, 1959

\section{Updated Information \& \\ Services}

Permissions \& Licensing

Reprints including high resolution figures, can be found at:

http://n.neurology.org/content/9/7/487.c itation.full

Information about reproducing this article in parts (figures,tables) or in its entirety can be found online at:

http://www.neurology.org/about/about the_journal\#permissions

Information about ordering reprints can be found online:

http://n.neurology.org/subscribers/adver tise

Neurology ${ }^{\circledR}$ is the official journal of the American Academy of Neurology.

Published continuously since 1951, it is now a weekly with 48 issues per year. Copyright (C) 1959 by the American Academy of Neurology. All rights reserved. Print ISSN: 0028-3878. Online ISSN: 1526-632X.

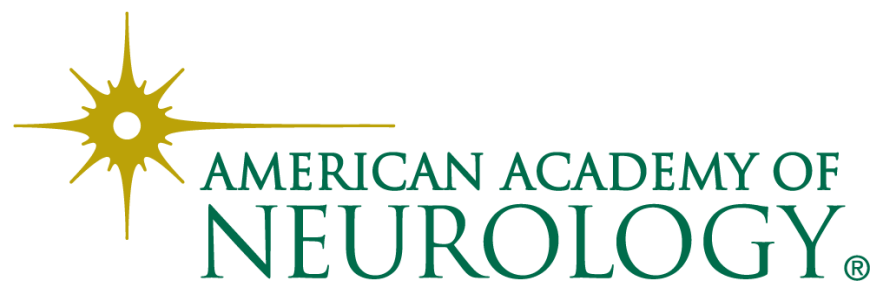

